\title{
The Effect of Blowing Ratio on Film Cooling Effectiveness Using Cylindrical and Row Trenched Cooling Holes with Alignment Angle of 90 Degrees
}

\author{
Nor Azwadi and Ehsan Kianpour \\ Faculty of Mechanical Engineering, Universiti Teknologi Malaysia (UTM), 81310 Johor Bahru, Malaysia \\ Correspondence should be addressed to Nor Azwadi; azwadi@fkm.utm.my
}

Received 26 July 2013; Revised 28 November 2013; Accepted 12 December 2013; Published 5 March 2014

Academic Editor: Youqing Wang

Copyright (C) 2014 N. Azwadi and E. Kianpour. This is an open access article distributed under the Creative Commons Attribution License, which permits unrestricted use, distribution, and reproduction in any medium, provided the original work is properly cited.

\begin{abstract}
This paper presents the effects of blowing ratio on film cooling performance adjacent to the combustor endwall using cylindrical and row trenched cooling holes with alignment angle of 90 degrees. A three-dimensional representation of a Pratt and Whitney gas turbine engine was simulated and analysed using a commercial finite volume package FLUENT 6.2.26. The combustor simulator was designed to combine the interaction of two rows of dilution jets, which were staggered in the streamwise direction and aligned in the spanwise direction. As a result, the combustor with row trenched holes gave almost doubled cooling performance compared to the baseline case. In addition, the film cooling layer was increased at high blowing ratio, and thus it enhanced the cooling performance.
\end{abstract}

\section{Introduction}

Gas turbine industries are searching for engine with higher efficiency. The Brayton cycle is an important key in this study. According to this cycle, the turbine inlet temperature should increase to gain more efficiency. However, increasing the turbine inlet temperature creates an extremely harsh environment for critical downstream components such as turbine vanes. Therefore, there is a need to design a cooling technique in this area. Film cooling is the conventional way used in the cooling technique. In this system, a thin thermal boundary layer such as buffer zone is formed and attached on the protected surface. Cylindrical and trenched cooling holes are two layouts of these holes. With trenching the cooling holes, the injected coolant is spread right before exiting the cooling holes and entering the main flow and, as a result, the coolant attached better on the surface.

Researchers have studied the effect of various cooling hole geometries for film cooling performance. Vakil and Thole [1] and Barringer et al. [2] presented the experimental results of the combustor simulator. They applied a real scale combustor, and the coolant flow and high momentum of dilution jets were injected into the main flow. They found that a high temperature gradient was developed upstream of the dilution holes. In addition, the results indicated that the dilution jets reduced the total pressure and velocity fields, and the turbulence level at the end of the combustor reached $24 \%$. This quantity is a little bit lower compared to Colban et al. [3] findings, which predicted the turbulence level between 25 and $30 \%$. Kianpour et al. $[4,5]$ simulated the same model using $k-\varepsilon$ and RNG $k-\varepsilon$ turbulent models to solve the Navier-Stokes equation. They claimed that the RNG $k-\varepsilon$ turbulent model was a good choice to detect the variation of temperature in the combustor simulator. This finding was later confirmed by Colban et al. [3], Patil et al. [6], and Scheepers and Morris [7]. They demonstrated the consistency of the results between experimental and numerical approaches by using the RNG $k-\varepsilon$ turbulent model.

In another study, Sundaram and Thole [8] and Baheri et al. [9] investigated the effects of modified trench depth in order to increase the film cooling effectiveness. The study was conducted with various individual and row trench depths. They reported that maximum cooling effectiveness can be obtained when the trench depth was $d=0.8 D$ ( $d$ is the trench 


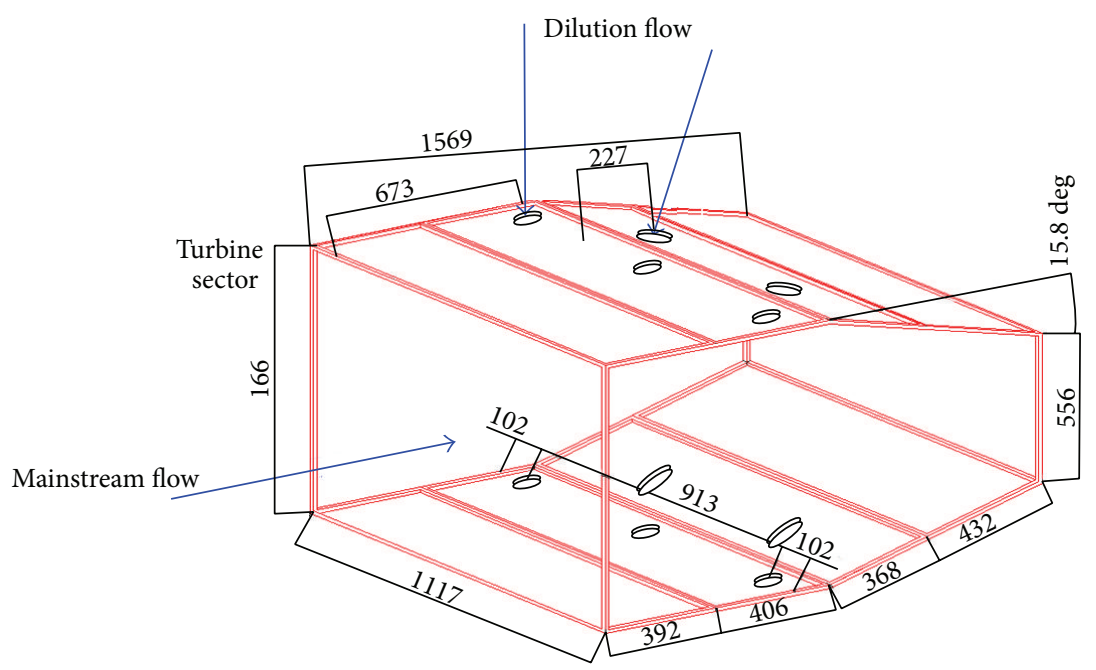

FIGURE 1: 3D view of the combustor simulator.

depth and $D$ is the diameter of the cooling hole). However, Lawson and Thole [10] found different results, suggesting that this trench depth gives negative effect on the cooling performance downstream the cooling hole. Later, Lu et al. [11] and Maikell et al. [12] found that the trench depth of $d=$ $0.75 \mathrm{D}$ gave the optimum efficiency and it was validated by CFD studies. In another study, Barigozzi et al. [13] suggested that high efficiency can be obtained when $d / D=1.0$ but it is restricted to low blowing ratio condition.

The effect of blowing ratio on the film cooling efficiency has also attracted few studies. Somawardhana and Bogard [14] investigated the effects of shallow trenched holes on the turbine vane cascade in the presence of obstructions. The adiabatic effectiveness was calculated for blowing ratios from 0.4 to 1.6. The results indicated that while upstream obstructions reduced the effectiveness by $50 \%$, the downstream obstructions increased the performance of film cooling for all blowing ratios. Furthermore, a combination of both obstructions slightly affected the performance of film cooling and the results were close to the case of upstream obstructions. They also concluded that the adiabatic effectiveness with the narrow trench was relatively constant across this range of blowing ratios. However, these results were inconsistent with Harrison et al. [15], Shuping [16], Baheri Islami and Jurban [17], and Lu and Ekkad [18], which stated that when the blowing ratio increased from 0.6 to 1.4 , the performance of the trench was three times greater than that for baseline cylindrical holes. Recently, Ai et al. [19] proved that trenching reduced the coolant momentum ratio and impaired the effectiveness while traditional cooling holes performance was better at low blowing ratios.

The study on film cooling efficiency using fan-shaped cooling was performed by Colban et al. [20, 21] for blowing ratios from 2.8 to 8.5 . They reported that for a constant blowing ratio, the fan-shaped holes increased film cooling effectiveness by an average of $75 \%$ over cylindrical holes. The above finding was consistent with the study by Peng and Jiang [22]. Peng and Jiang [22] examined the effect of blowing ratio in the range of 0.5 to 1.5 on the film cooling effectiveness using fan-shaped cooling holes. They concluded that the film cooling performance increased as the blowing ratio increased, which differs from that of the cylindrical hole. For the case of fan-shaped hole model, as the blowing ratio increased, the cooling gas flow rate increased; hence there is more cooling gas to protect the wall, and the film cooling effectiveness increased. In addition, according to Lutum et al. [23] and Gao et al. [24], higher film cooling performance was observed for the shaped holes at higher blowing ratios compared to cylindrical cases.

It appears from the aforementioned investigations that numerous investigations have been conducted on the effects of internal cooling holes. However, no attempt was made to investigate the effects of trenching the cooling holes near the combustor endwall surface on the film cooling effectiveness. The primary zone which senses this high temperature gas is the combustor endwall surface. Developing more effective cooling that covers the area adjacent to the wall is important because without this layer, the outlet combustion temperature increment is not reasonable. It threatens the life of the endwall surface of the combustor and imposes high costing services to the customers. Furthermore, the improvement of film cooling layer adjacent to the combustor endwall surface assists the designers to make better operable condition for the engine, as well as increasing the efficiency. Therefore, the objective of the present study was to investigate the change of film cooling effectiveness with different arrangements of cooling holes as the baseline case and trenched holes at different blowing ratios.

\section{Methods and Materials}

In this study, a three-dimensional representation of a true Pratt and Whitney engine was simulated and analyzed to gain essential data. The schematic view of the combustor is shown in Figure 1. The width and inlet height of the final combustor simulator design was $111.8 \mathrm{~cm}$ and $99.1 \mathrm{~cm}$, respectively. 


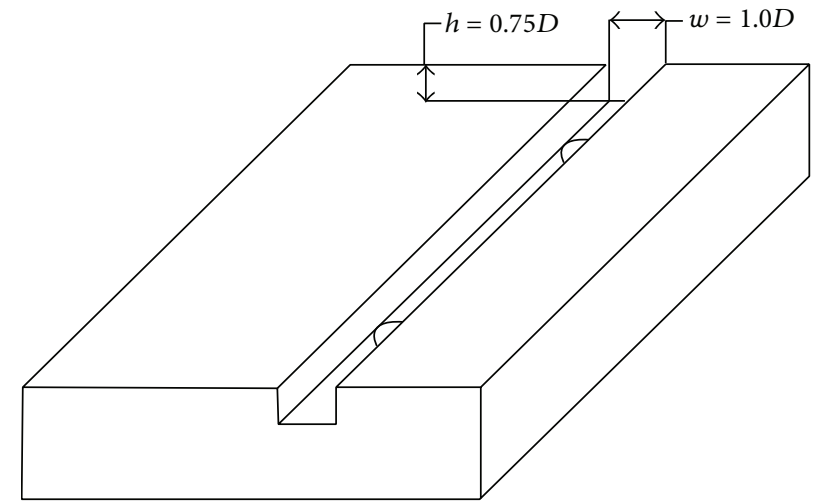

FIGURE 2: Schematic geometry of row trenched cooling holes with alignment angle of 90 degrees.

The length of the combustor was $156.9 \mathrm{~cm}$ and the contraction angle was 15.8 degrees. The contraction angle began at $X=79.8 \mathrm{~cm}$. The inlet cross-sectional area was $1.11 \mathrm{~m}^{2}$ and the exit cross-sectional area was reduced to $0.62 \mathrm{~m}^{2}$. The combustor simulator included four film-cooled streamwise panels. The starting point of these panels was approximately at $1.6 \mathrm{~m}$ upstream of the turbine vanes. The first and second panels were 39.2 and $40.6 \mathrm{~cm}$ in length, respectively. The length of the next two panels was $36.8 \mathrm{~cm}$ and $43.2 \mathrm{~cm}$. The low thermal conductivity of combustor panels were $1.27 \mathrm{~cm}$ in thickness, which allowed for adiabatic surface temperature measurements. Two different rows of dilution holes were considered within the second and third panels. These dilution rows were located at $0.67 \mathrm{~m}$ and $0.90 \mathrm{~m}$ downstream of the beginning of the combustor liner panels. The diameter of the dilution holes at the first and second rows was $8.5 \mathrm{~cm}$ and $11.9 \mathrm{~cm}$, respectively.

The centre line of the second row was staggered with respect to the first row of dilution holes. To verify the purpose of this study, a three-dimensional representation of a Pratt and Whitney gas turbine engine was simulated. The present combustor simulator included two configurations of cooling holes. The first arrangement (baseline) was designed similar to Vakil and Thole [1]. In both cases, the film cooling holes were placed in equilateral triangles. The diameter of the film cooling holes was $0.76 \mathrm{~cm}$ and drilled at an angle of 30 degrees from the horizontal surface. The length of film cooling holes in the baseline case was $2.5 \mathrm{~cm}$. For the second case (Case 2 ), the cooling holes were embedded within a row trenched with alignment angle of 90 degrees, as shown in Figure 2. Furthermore, the trench depth and width were $0.75 \mathrm{D}$ and $1.0 D$, respectively.

The purpose of this study was to investigate the effects of cooling holes structure on the film cooling effectiveness within a combustor simulator at different coolant blowing ratios. In comparing the results, a number of nondimensional parameters need to be defined. The dimensionless variables were defined for both the coolant and the dilution flow. Table 1 gives a complete description of the operating conditions for the main flow, while Table 2 shows the
TABLE 1: Typical operating condition for main flow.

\begin{tabular}{lc}
\hline Parameter & Quantity \\
\hline Main flow pressure (Kilopascal) & 98.82 \\
Main flow temperature $\left({ }^{\circ} \mathrm{K}\right)$ & 332 \\
Main flow velocity $(\mathrm{m} / \mathrm{s})$ & 1.62 \\
Main flow density $\left(\mathrm{kg} / \mathrm{m}^{2}\right)$ & 1.0 \\
\hline
\end{tabular}

TABLE 2: Flow dimensional parameters for cooling holes and dilution jets.

\begin{tabular}{lccc}
\hline Parameter & Location & Quantity \\
\hline Density ratio & Dilution row 1 & 1.12 & \\
$\mathrm{DR}=\frac{\rho_{\text {jet }}}{\rho_{\infty}}$ & Dilution row 2 & 1.12 & \\
\hline \multirow{2}{*}{ Mass flux ratio $(M)$} & Cooling panels & 1.12 & \\
$M=\frac{\rho_{\text {jet }} u_{\text {jet }}}{\rho_{\infty} u_{\infty}}$ & Dilution row 1 & 11.99 & \\
& Dilution row 2 & 6.0 & \\
& Cooling panels & First case & 3.18 \\
\hline
\end{tabular}

nondimensional parameters of the dilution jets and coolant, respectively.

Also, the temperature of the coolant and dilution jets was considered equal to $295.5^{\circ} \mathrm{K}$. The thermal distribution inside a combustor simulator was measured along the specific measurement planes. These measurement planes are shown in Figure 3. In order to get more accurate data and reasonable time consumption, about $8 \times 10^{6}$ tetrahedral meshes were used as adopted in the study by Stitzel and Thole [25].

According to the specific flow ratio at the inlet of volume control, inlet mass flow boundary condition was defined. Wall boundary condition and slipless boundary condition were applied to limit the interaction zone between fluid and solid layer. The pressure outlet boundary condition was used at the end of volume control. In addition, both cases were completely symmetrical along the $X-Y$ and $X-Z$ planes. According to this issue, symmetry boundary condition $\partial / \partial n=0$ was as applied. In addition, the following equations were used as well.

The governing equations for the current study case are the momentum equation

$$
\begin{aligned}
\frac{\partial}{\partial x_{j}}\left(\rho u_{i} u_{j}\right)= & -\frac{\partial p}{\partial x_{i}}+\frac{\partial}{\partial x_{j}}\left[\mu\left(\frac{\partial u_{i}}{\partial x_{j}}+\frac{\partial u_{j}}{\partial x_{i}}\right)\right] \\
& +\frac{\partial}{\partial x_{j}}\left(-\rho \overline{u_{i}^{\prime} u_{j}^{\prime}}\right),
\end{aligned}
$$

the continuity equation

$$
\frac{\partial}{\partial x_{i}}\left(\rho u_{i}\right)=0
$$




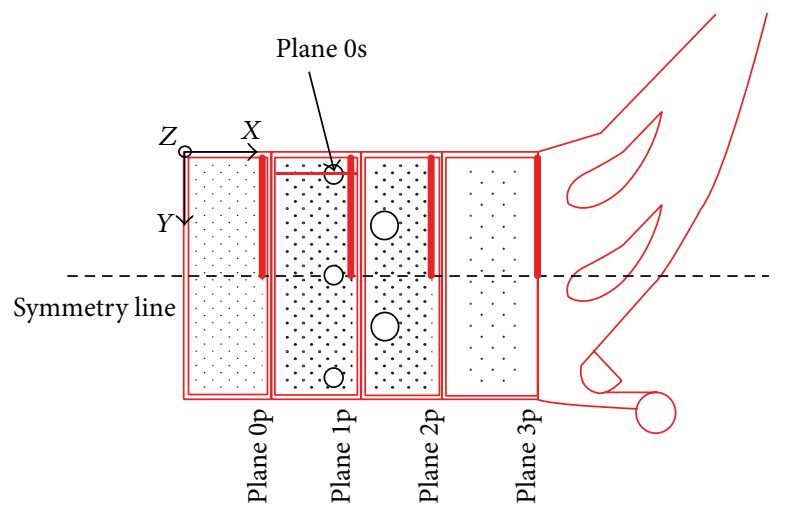

(a)

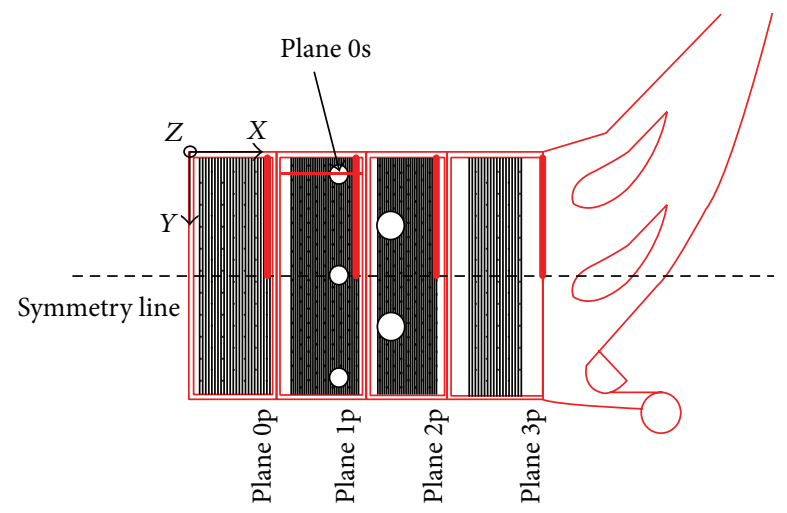

(b)

FIGURE 3: Location of the measurement planes for (a) baseline and (b) Case 2.

and the energy and RNG $k-\varepsilon$ equations

$$
\begin{gathered}
\frac{\partial}{\partial x_{i}}\left(\rho u_{i} T\right)=\frac{\partial}{\partial x_{j}}\left(\left(\Gamma+\Gamma_{t}\right) \frac{\partial}{\partial x_{j}}\right) \\
\frac{\partial}{\partial x_{i}}\left(\rho k u_{i}\right)=\frac{\partial}{\partial x_{j}}\left[\left(\mu+\frac{\mu_{t}}{\sigma_{k}}\right) \frac{\partial k}{\partial x_{j}}\right]+P_{k}-\rho \epsilon \\
\frac{\partial}{\partial x_{i}}\left(\rho \epsilon u_{i}\right)=\frac{\partial}{\partial x_{j}}\left[\left(\mu+\frac{\mu_{t}}{\sigma_{\epsilon}}\right) \frac{\partial \epsilon}{\partial x_{j}}\right]+C_{1 \epsilon} \frac{\epsilon}{k} P_{k}-C_{2 \epsilon}^{*} \rho \frac{\epsilon^{2}}{k} .
\end{gathered}
$$

The first-order upwind and central differencing scheme were used to approximate the convective and diffusion terms in the differential equation, respectively. To check the convergence, the mass residue of each control volume has been calculated and the maximum value has been used to check for the convergence. The convergence criterion has been set to $10^{-4}$.

To understand the thermal field results, the quantities should be defined. Film cooling effectiveness is defined as below:

$$
\eta=\frac{T-T_{\infty}}{T_{C}-T_{\infty}}
$$

In the equation above, $T$ is the local temperature, $T_{\infty}$ is the main stream temperature, and $T_{C}$ is the temperature of coolant.

\section{Results and Discussion}

Comparisons have been made for baseline case using the experimental results by Vakil and Thole [1], computational results by Stitzel and Thole [25], and the current study. The model used in this computational study was the RNG $k-\varepsilon$ model. The biggest difference between the standard and RNG models is the addition of the $R$ term in the transport equation for turbulence dissipation. This term makes the RNG model more responsive to the effects of rapid strain and streamline curvature, thus improving the model, particularly for separated flows, and recirculating flows and endwall

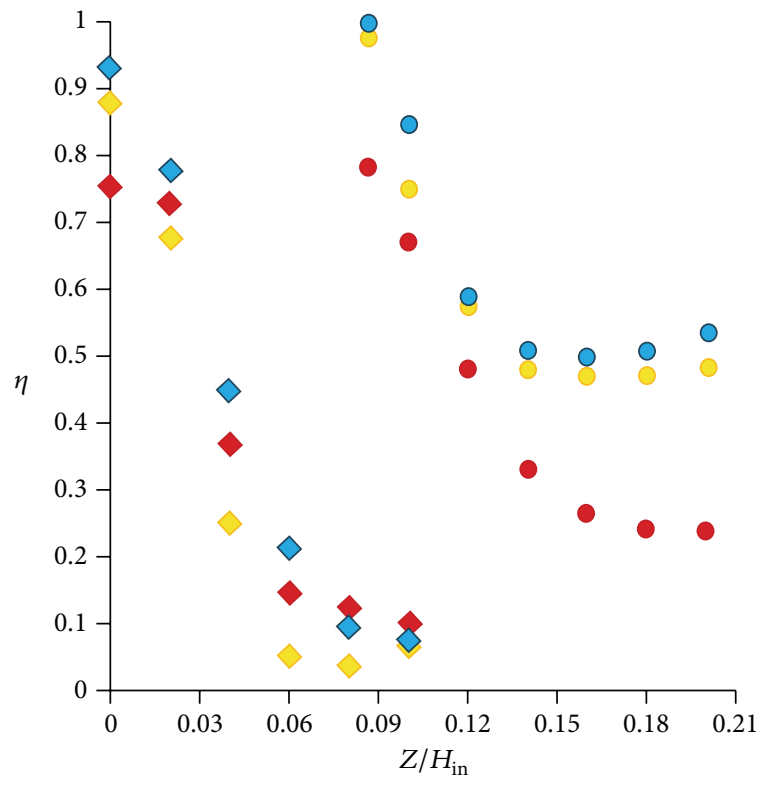

Current study, plane $1 \mathrm{p}$

Experimental (Vakil and Thole, 2005), plane 1p

$\diamond$ CFD prediction (Stitzel and Thole, 2004), plane 1p

- Current study, plane $2 \mathrm{p}$

Experimental (Vakil and Thole, 2005), plane 2p

O CFD prediction (Stitzel and Thole, 2004), plane 2p

FIGURE 4: Comparison of film cooling effectiveness for plane $1 \mathrm{p}$ and $2 \mathrm{p}$ along $Y / W=0.4$.

secondary flows. Figure 4 presents the comparison of film cooling effectiveness for plane $1 \mathrm{p}$ and $2 \mathrm{p}$ at $Y / W=0.4$. The deviations between the current computation and benchmarks were calculated as follows:

$$
\% \text { Diff }=\frac{\sum_{i=1}^{n}\left(x_{i}-x_{i, \text { benchmark }}\right) / x_{i, \text { benchmark }}}{n} \times 100 \text {. }
$$

According to this formula, the deviation was equal to 9.76\% and $8.34 \%$ compared to $[1,25]$ for plane $1 p$ and equal to $13.36 \%$ and $11.96 \%$ compared to $[1,25]$ for plane $2 p$. 


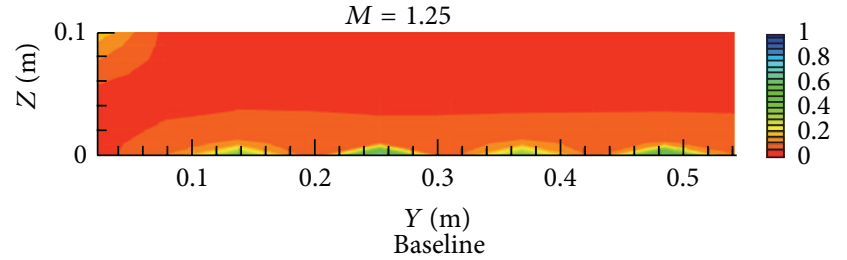

(a)

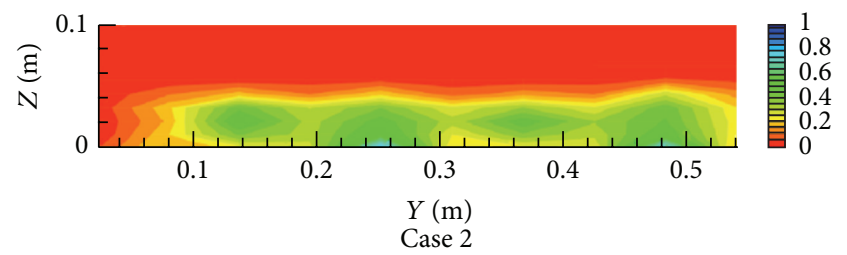

(c)

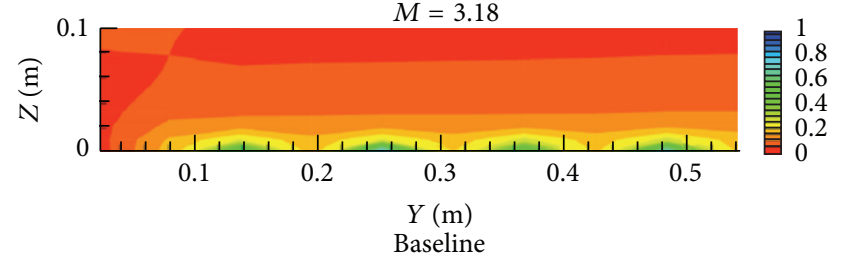

(b)

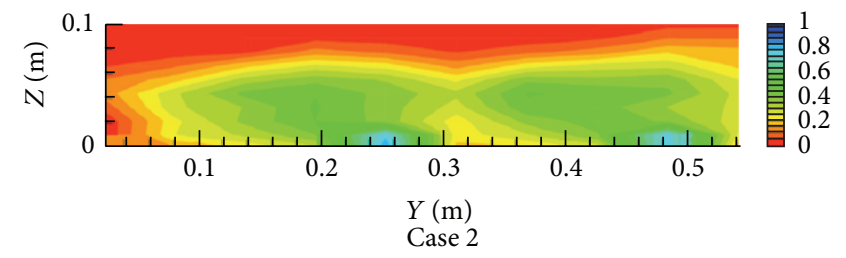

(d)

Figure 5: Distribution of film cooling effectiveness of plane $0 \mathrm{p}$ for different configurations and blowing ratios of $M=1.25$ and $M=3.18$.

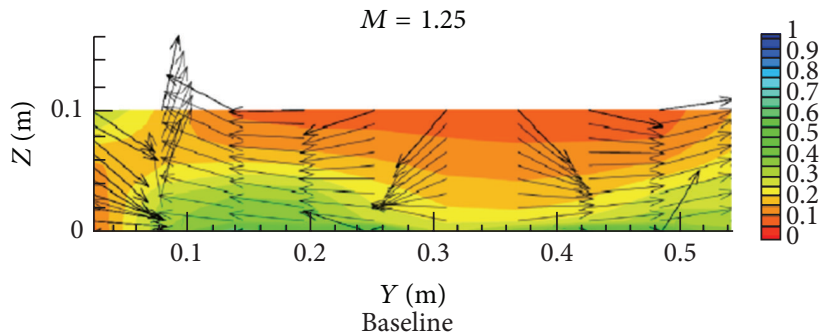

(a)

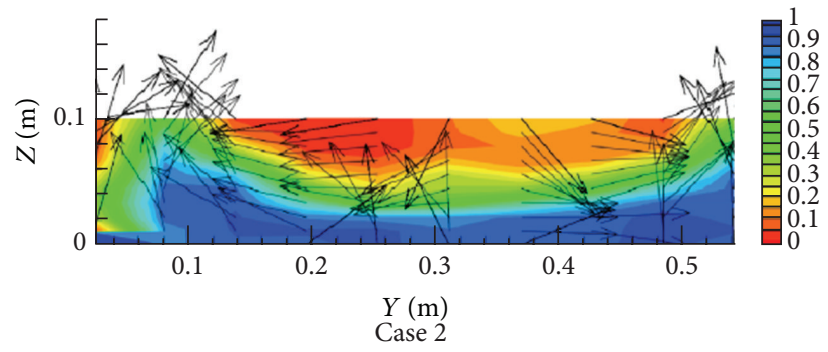

(c)

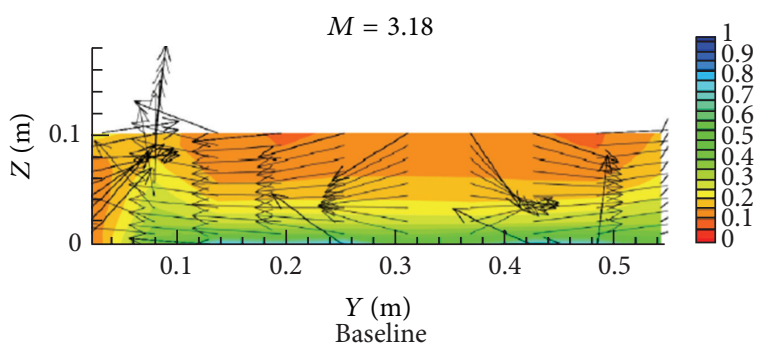

(b)

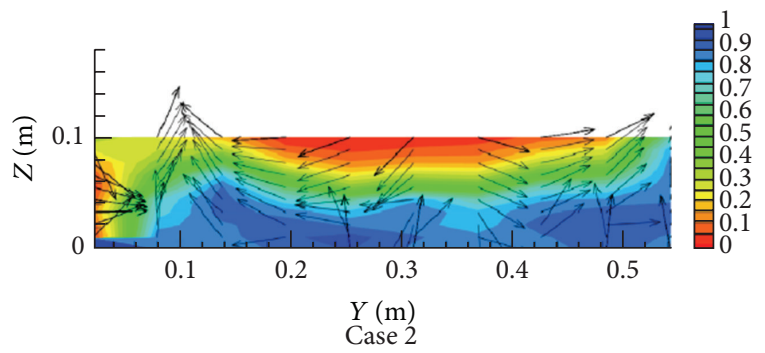

(d)

FiguRE 6: Vectors of $v$ and $w$ with film cooling effectiveness contours of plane $1 \mathrm{p}$ for different configurations and blowing ratios of $M=1.25$ and $M=3.18$.

The film cooling distribution of plane $0 \mathrm{p}$ under two different blowing ratios $(M=1.25$ and $M=3.18)$ is illustrated in Figure 5. A significant difference between these figures was the layer of film cooling thickness. Meanwhile, for the trenched condition, the thickness of this layer reached $Z=50 \mathrm{~mm}$ at blowing ratio of 1.25 , and for the blowing ratio of $M=3.18$, it reached $Z=90 \mathrm{~mm}$. However, for this measurement plane, the thicker film cooling layer for the trenched hole did not automatically suggest that it was desirable. Definitely, for the trenched case and at a position of $31 \mathrm{~cm}<Y<36 \mathrm{~cm}$, the temperature level was higher near the endwall surface at $M=3.18$ compared to the temperature distribution contour of Case 2 and at blowing ratio of $M=$ 1.25 .
The film cooling effectiveness distribution of plane $1 \mathrm{p}$ at two different blowing ratios of $M=1.25$ and $M=$ 3.18 is illustrated in Figure 6. The film cooling effectiveness increased significantly for both ratios. At the right side $(50 \mathrm{~cm}<Y<54 \mathrm{~cm})$ of thermal field contours and for both blowing ratios, film cooling was entrained by the upward motion of dilution jet. Also, at the positions of $18 \mathrm{~cm}<Y<$ $40 \mathrm{~cm}$ and $8 \mathrm{~cm}<Z<10 \mathrm{~cm}$, it was slightly hotter $(0<$ $\eta<0.05$ ) for the trenched case at $M=3.18$, as opposed to the baseline. However, for both mass flux ratios and adjacent to the endwall surface, row trenched hole performed better compared to the baseline. The $v$ and $w$ velocity vectors of plane $1 p$ are shown as well. Due to the effect of dilution injection on the thermal behavior of flow at the middle of 


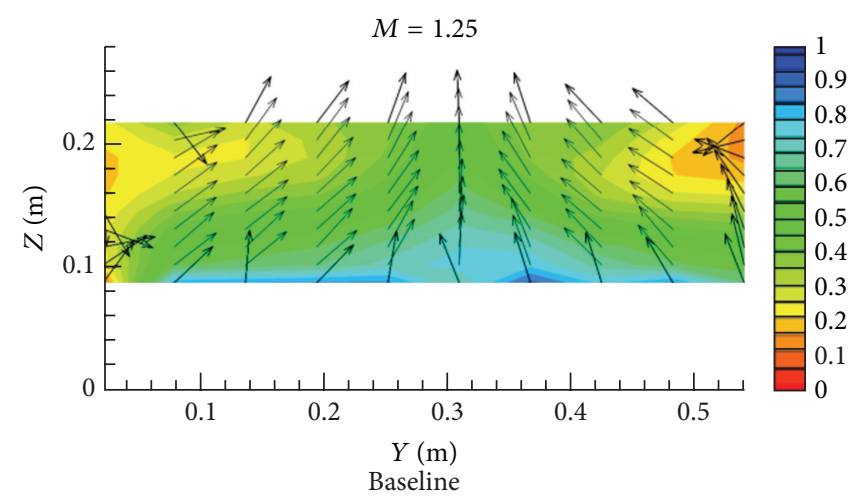

(a)

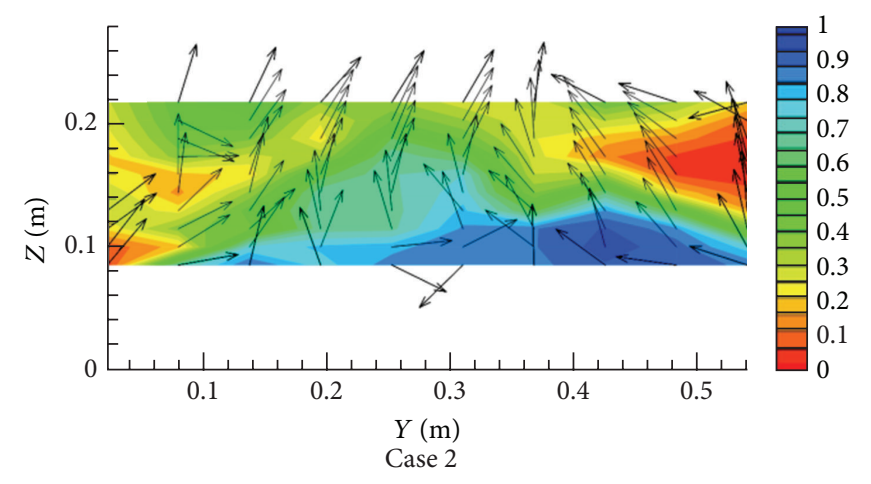

(c)

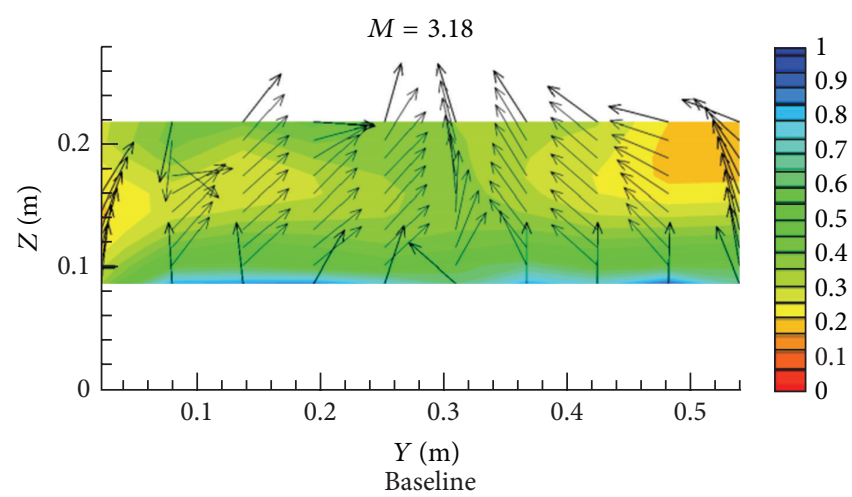

(b)

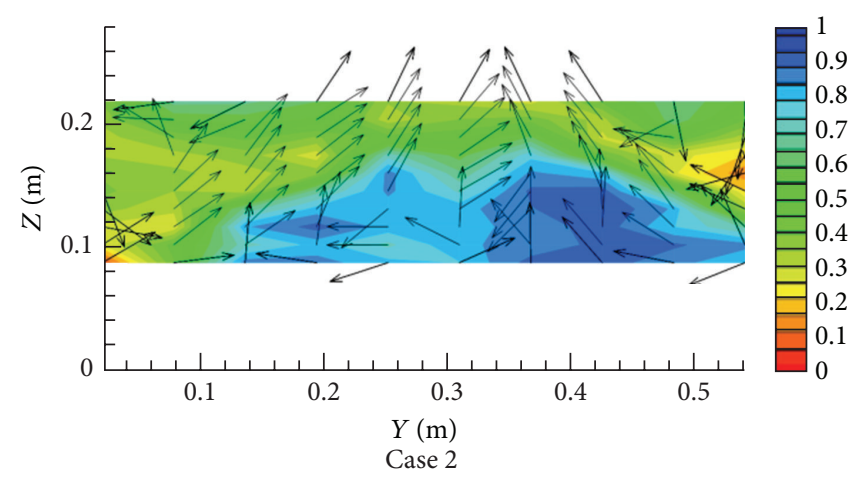

(d)

FIGURE 7: Vectors of $v$ and $w$ with film cooling effectiveness contours of plane $2 \mathrm{p}$ for different configurations and blowing ratios of $M=1.25$ and $M=3.18$.

the temperature distribution contour, a significant movement of vortexes towards the left and right sides was observed.

Figure 7 shows the distribution of film cooling effectiveness for plane $2 \mathrm{p}$ under blowing ratios of $M=1.25$ and $M=3.18$. It was highlighted from the contours that the rotating flow was seen on the left side and was entrained along the spanwise direction. However, with the increase of mass flux ratio, this rotating flow became weaker, especially for the trenched case. In addition, the lack of uniformity within the combustor exiting profile at this point was overwhelmingly apparent. Also, at the right side of the film cooling effectiveness distribution for baseline, it was found that hot gases covered more extended area in comparison with the trenched cases. Note that the film cooling effectiveness reduction happened due to the enhancement of blowing ratio for the baseline. Lastly, these figures show the $v$ and $w$ velocity vectors superimposed on the thermal field contours of this measurement plane. The sweeping of the coolant towards the second row of dilution jet was visible for all cases.

The variations of film cooling effectiveness for different measurement planes and mass flux ratios at $Y=30 \mathrm{~cm}$ and along $Z$ axis are shown in Figure 8. For the measurement of planes $0 \mathrm{p}$ and $1 \mathrm{p}$ and for all configurations, the increase of film cooling effectiveness occurred with the enhancement of blowing ratio. Meanwhile, for the plane $2 \mathrm{p}$, the film cooling performance reduced about $12 \%$ with the increase of blowing ratio for the baseline. Lastly for plane $3 p$, the film cooling effectiveness of baseline increased intensively (58\%), which was higher than the trenched cases at high blowing ratio. Also, it was found that Case 2 has severe effect on the enhancement of film cooling performance with the increase of blowing ratio, especially for the measurement planes of $0 \mathrm{p}$ and $1 \mathrm{p}$, with the enhancement ratio of $180 \%$ and $203 \%$, respectively.

Figure 9 shows the streamwise film cooling distribution through a first row of dilution jet for all configurations at $M=1.25$ and $M=3.18$. Note that at the position of $60 \mathrm{~cm}<$ $X<72 \mathrm{~cm}$, the dilution jet injected into the mainstream and the coolest region was created. Furthermore, upstream the dilution jet, the hot region approximately disappeared for the trenched cases and it happened due to the effects of coolant penetration from the trenched cooling holes.

\section{Conclusion and Recommendation}

The objective of this study was to analyze the effects of different blowing ratios of $M=1.25$ and $M=3.18$ on the film cooling effectiveness with different cooling holes configurations of cylindrical and row trenched holes with the alignment angle of 90 degrees at the end of the combustor simulator. In this study, a three-dimensional representation of a Pratt and Whitney engine was simulated and analyzed. To sum up, for all layouts, the film cooling layer grows 


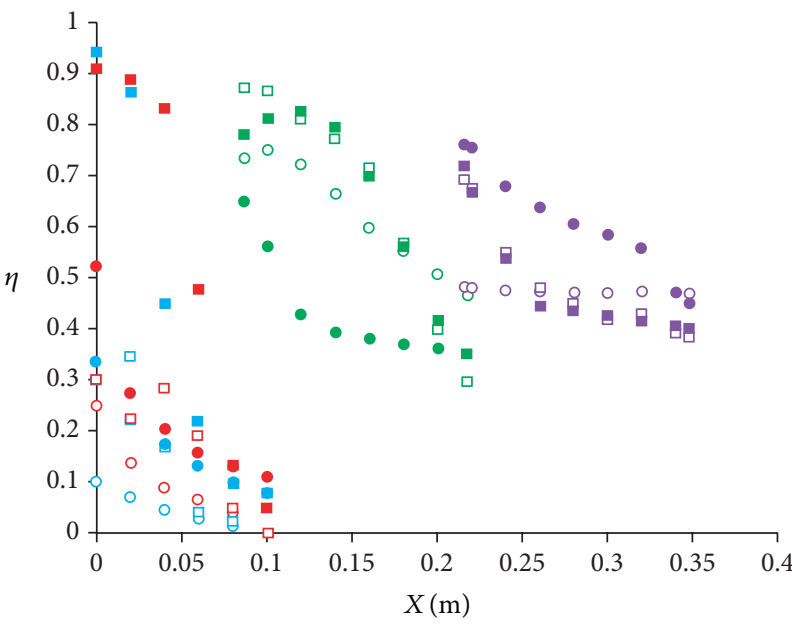

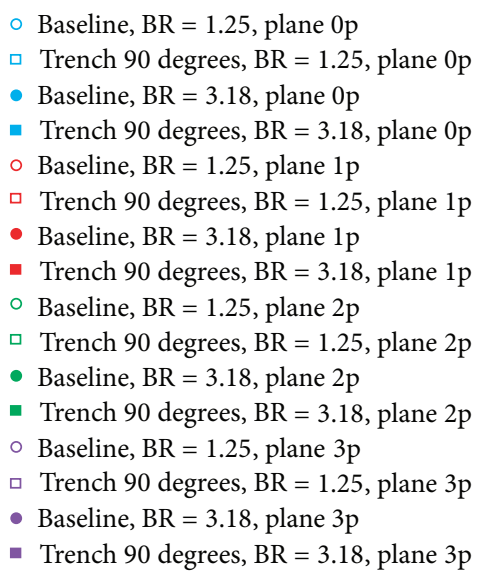

Figure 8: The changes of film cooling effectiveness for different configurations.

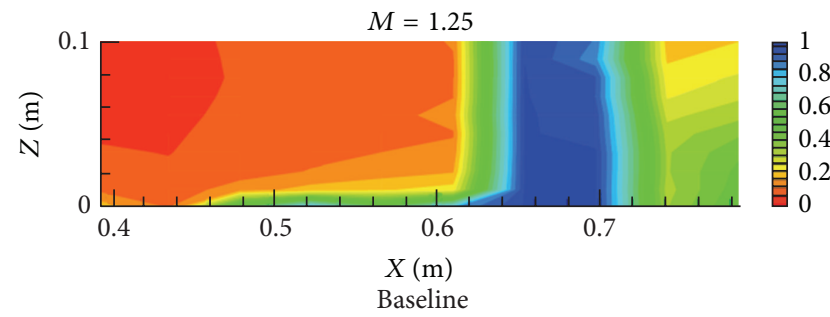

(a)

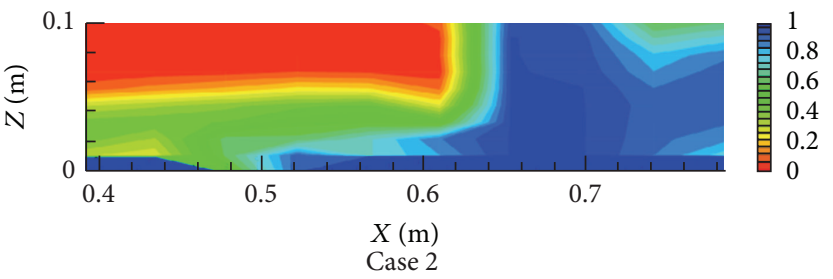

(c)

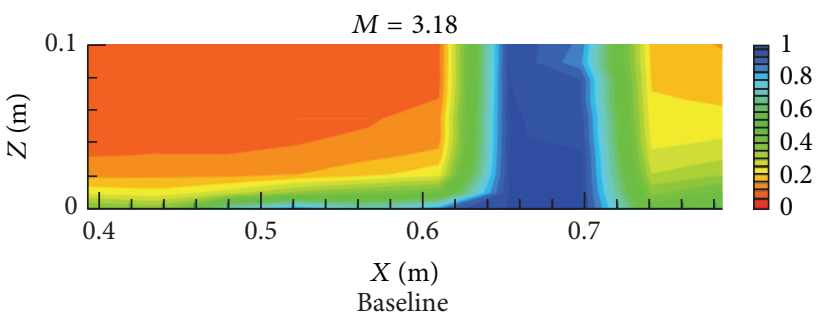

(b)

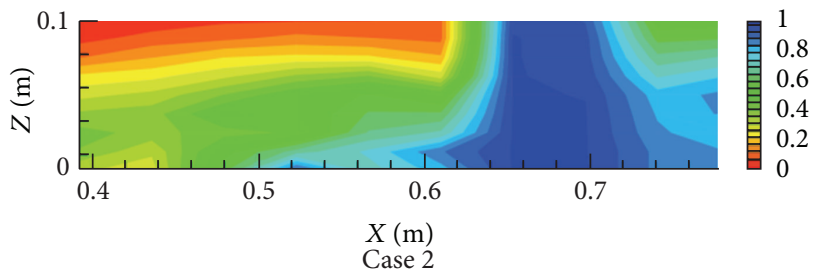

(d)

FIGURE 9: Film cooling effectiveness distribution of plane $0 p$ for different configurations and blowing ratios $M=1.25$ and $M=3.18$. 
at high mass flux ratio, and it becomes thinner by using cylindrical holes for plane $2 \mathrm{p}$. Also, the central part of the plane $2 p$ showed the intense penetration of the coolant and a thick film cooling layer was created in the trenched cases. On the other hand, the increase of blowing ratio led to a cooler region adjacent to the wall and between the jets, especially for the trenched cases. The thermal field findings demonstrated a recirculation area developing exactly downstream of the jet, where the entrainment of film cooling was caused by the dilution jet. The contours of the streamwise thermal field indicated the intense effect of trenched cooling holes and dilution injection downstream the dilution jet, particularly for the trenched holes and elevated mass flux ratio. For the measurement planes $0 \mathrm{p}$ and $1 \mathrm{p}$ and for all configurations, the film cooling effectiveness increased with blowing ratio enhancement, while for the plane $2 p$, the film cooling performance reduced with the increase of blowing ratio for the baseline. Based on the results and conclusions of the study, there are several recommendations to consider. In future research within this area, it is strongly recommended to use the trenched holes for the second and third cooling panels as trenching cooling holes have better effect on film cooling performance at higher blowing ratio.

\section{Conflict of Interests}

The authors declare that they have no conflict of interests regarding the publication of this paper.

\section{Acknowledgment}

The authors would like to acknowledge Universiti Teknologi Malaysia and Ministry of Higher Education of Malaysia for supporting this research. This research is financially supported by Transport Research Alliance, Universiti Teknologi Malaysia.

\section{References}

[1] S. S. Vakil and K. A. Thole, "Flow and thermal field measurements in a combustor simulator relevant to a gas turbine aeroengine," Journal of Engineering for Gas Turbines and Power, vol. 127, no. 2, pp. 257-267, 2005.

[2] M. D. Barringer, O. T. Richard, J. P. Walter, S. M. Stitzel, and K. A. Thole, "Flow field simulations of a gas turbine combustor," Journal of Turbomachinery, vol. 124, no. 3, pp. 508-516, 2002.

[3] W. F. Colban, A. T. Lethander, K. A. Thole, and G. Zess, "Combustor turbine interface studies-part 2: flow and thermal field measurements," Journal of Turbomachinery, vol. 125, no. 2, pp. 203-209, 2003.

[4] E. Kianpour, C. S. Nor Azwadi, and M. Agha Seyyed Mirza Bozorg, "Thermodynamic analysis of flow field at the end of combustor simulator," International Journal of Heat and Mass Transfer, vol. 61, pp. 389-396, 2013.

[5] E. Kianpour, C. S. Nor Azwadi, and M. Agha Seyyed Mirza Bozorg, "Dynamic analysis of flow field at the end of combustor simulator," Jurnal Teknologi, vol. 58, pp. 5-12, 2012.

[6] S. Patil, S. Abraham, D. Tafti et al., "Experimental and numerical investigation of convective heat transfer in a gas turbine can combustor," Journal of Turbomachinery, vol. 133, no. 1, Article ID 011028, pp. 1-7, 2011.

[7] G. Scheepers and R. M. Morris, "Experimental study of heat transfer augmentation near the entrance to a film cooling hole in a turbine blade cooling passage," Journal of Turbomachinery, vol. 131, no. 4, Article ID 011028, pp. 1-11, 2009.

[8] N. Sundaram and K. A. Thole, "Bump and trench modifications to film-cooling holes at the vane-endwall junction," Journal of Turbomachinery, vol. 130, no. 4, Article ID 041013, pp. 1-9, 2008.

[9] S. Baheri, S. P. A. Tabrizi, and B. A. Jubran, "Film cooling effectiveness from trenched shaped and compound holes," Heat and Mass Transfer, vol. 44, no. 8, pp. 989-998, 2008.

[10] S. A. Lawson and K. A. Thole, "Simulations of multiphase particle deposition on end wall film-cooling holes in transverse trenches," Journal of Turbomachinery, vol. 134, Article ID 051040, pp. 1-10, 2012.

[11] Y. Lu, A. Dhungel, S. V. Ekkad, and R. S. Bunker, "Effect of trench width and depth on film cooling from cylindrical holes embedded in trenches," Journal of Turbomachinery, vol. 131, no. 1, Article ID 011003, pp. 1-13, 2009.

[12] J. Maikell, D. Bogard, J. Piggush, and A. Kohli, "Experimental simulation of a film cooled turbine blade leading edge including thermal barrier coating effects," Journal of Turbomachinery, vol. 133, no. 1, Article ID 011014, pp. 1-7, 2011.

[13] G. Barigozzi, G. Franchini, A. Perdichizzi, and S. Ravelli, "Effects of trenched holes on film cooling of a contoured endwall nozzle vane," Journal of Turbomachinery, vol. 134, no. 4, Article ID 041009, pp. 1-10, 2011.

[14] R. P. Somawardhana and D. G. Bogard, "Effects of obstructions and surface roughness on film cooling effectiveness with and without a transverse trench," Journal of Turbomachinery, vol. 131, no. 1, Article ID 011010, pp. 1-8, 2009.

[15] K. L. Harrison, J. R. Dorrington, J. E. Dees, D. G. Bogard, and R. S. Bunker, "Turbine airfoil net heat flux reduction with cylindrical holes embedded in a transverse trench," Journal of Turbomachinery, vol. 131, no. 1, Article ID 011012, pp. 1-8, 2009.

[16] C. Shuping, Film cooling enhancement with surface restructure [Ph.D. thesis], University of Pittsburgh, Pittsburgh, Pa, USA, 2008.

[17] S. Baheri Islami and B. A. Jubran, "The effect of turbulence intensity on film cooling of gas turbine blade from trenched shaped holes," Heat and Mass Transfer, vol. 48, no. 5, pp. 831840, 2011.

[18] Y. Lu and S. V. Ekkad, "Predictions of film cooling from cylindrical holes embedded in trenches," in Proceedings of the 9th AIAA/ASME Joint Thermophysics and Heat Transfer Conference Proceedings, pp. 1361-1369, AIAA/ASME, San Francisco, Calif, USA, June 2006.

[19] W. Ai, R. G. Laycock, D. S. Rappleye, T. H. Fletcher, and J. P. Bons, "Effect of particle size and trench configuration on deposition from fine coal flyash near film cooling holes," Energy and Fuels, vol. 25, no. 3, pp. 1066-1076, 2011.

[20] W. Colban, K. A. Thole, and M. Haendler, "A comparison of cylindrical and fan-shaped film-cooling holes on a vane endwall at low and high freestream turbulence levels," Journal of Turbomachinery, vol. 130, no. 3, Article ID 031007, 2008.

[21] W. Colban, A. Gratton, K. A. Thole, and M. Haendler, "Heat transfer and film-cooling measurements on a stator vane with fan-shaped cooling holes," Journal of Turbomachinery, vol. 128, no. 1, pp. 53-61, 2006. 
[22] W. Peng and P. X. Jiang, "Experimental and numerical study of film cooling with internal coolant cross-flow effects," Experimental Heat Transfer, vol. 25, no. 4, pp. 282-300, 2012.

[23] E. Lutum, J. Von Wolfersdorf, K. Semmler, S. Naik, and B. Weigand, "Film cooling on a convex surface: influence of external pressure gradient and Mach number on film cooling performance," Heat and Mass Transfer, vol. 38, no. 1, pp. 7-16, 2002.

[24] Z. Gao, D. Narzary, and J.-C. Han, "Turbine blade platform film cooling with typical stator-rotor purge flow and discrete-hole film cooling," Journal of Turbomachinery, vol. 131, no. 4, Article ID 041004, pp. 1-11, 2009.

[25] S. Stitzel and K. A. Thole, "Flow field computations of combustor-turbine interactions relevant to a gas turbine engine," Journal of Turbomachinery, vol. 126, no. 1, pp. 122-129, 2004. 


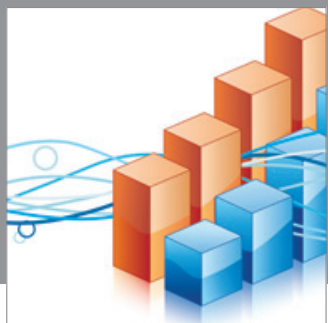

Advances in

Operations Research

mansans

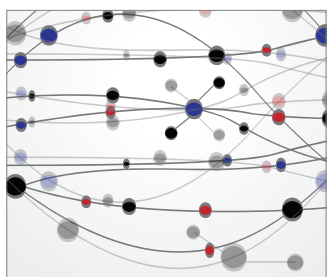

The Scientific World Journal
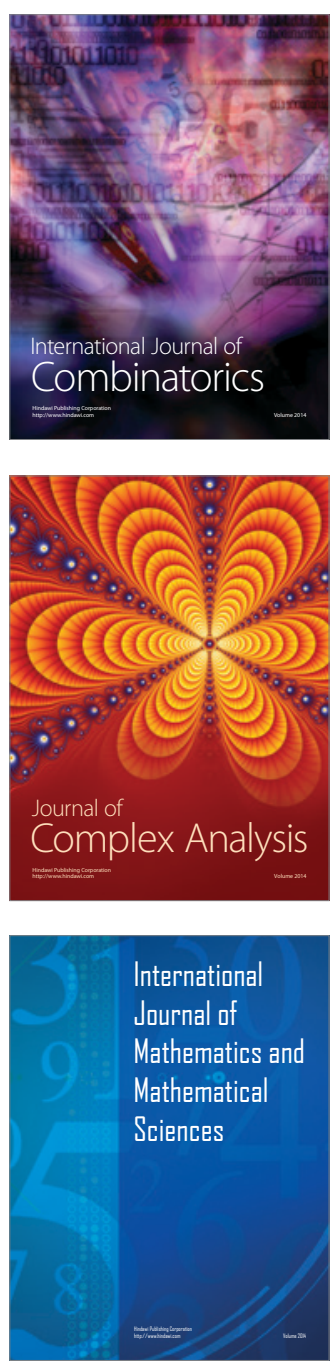
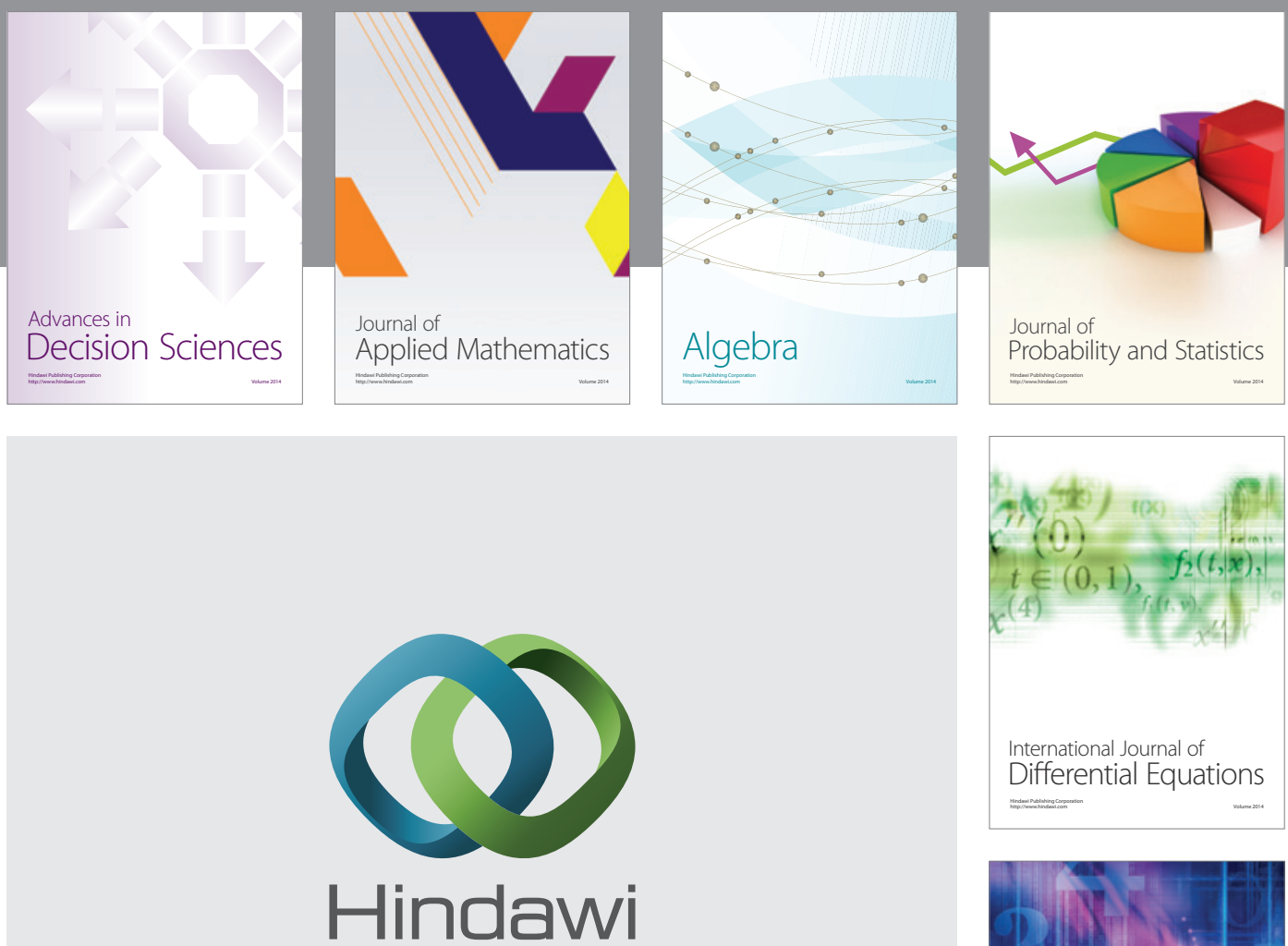

Submit your manuscripts at http://www.hindawi.com
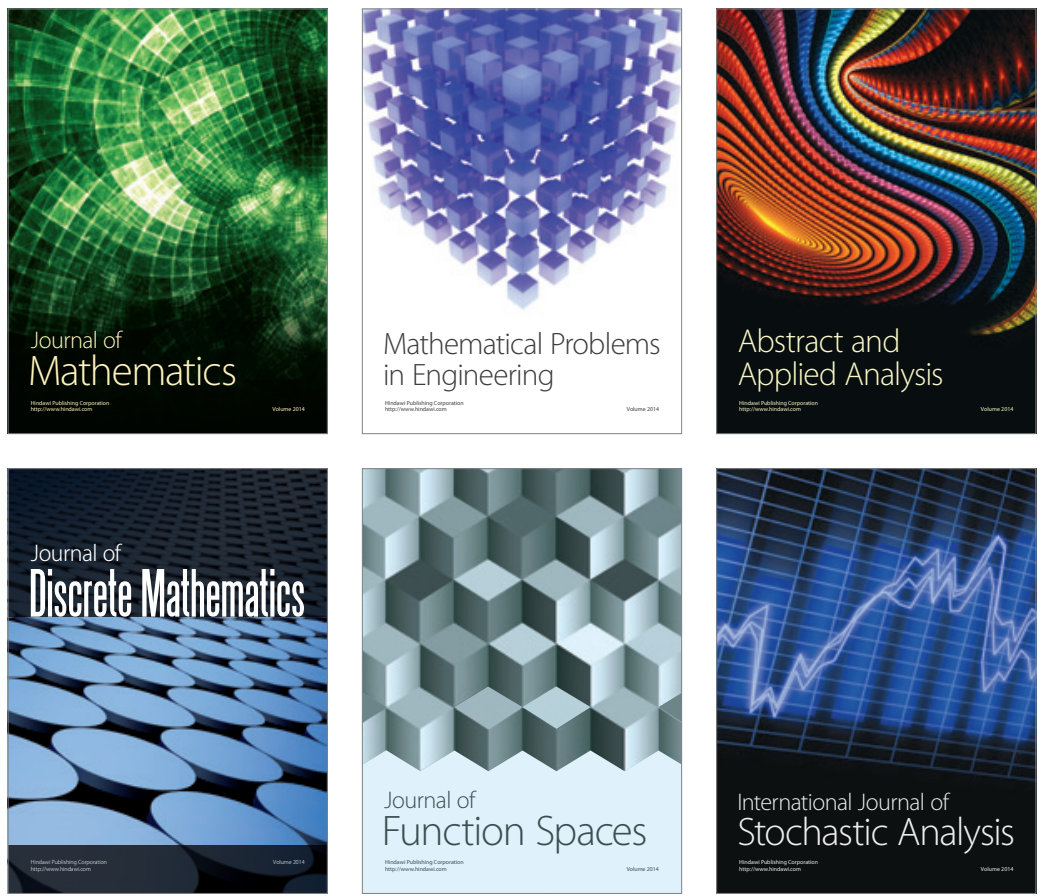

Journal of

Function Spaces

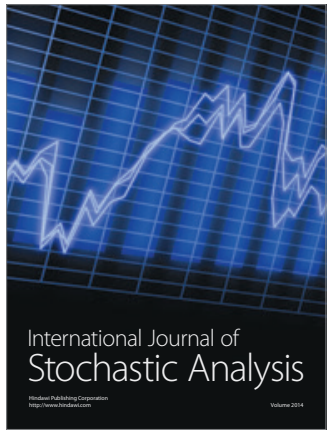

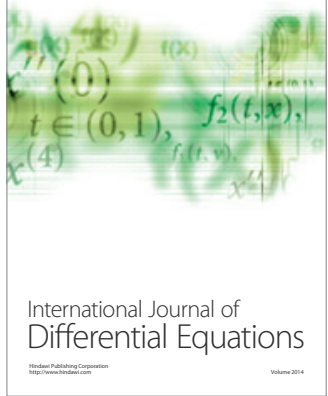
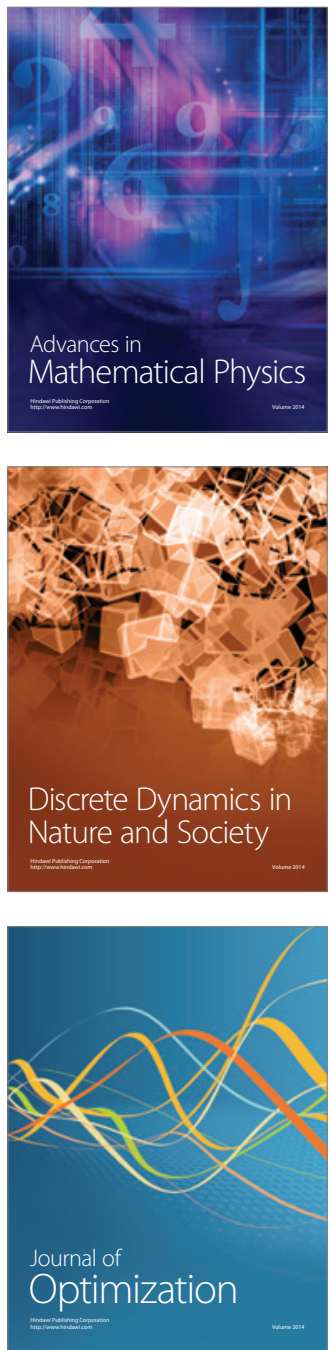